\title{
Elimination of visually evoked BOLD responses during carbogen inhalation: Implications for calibrated MRI
}

\author{
C.J. Gauthier ${ }^{\mathrm{a}, \mathrm{b}, *}$, C. Madjar ${ }^{\mathrm{b}}$, F.B. Tancredi ${ }^{\mathrm{a}, \mathrm{b}}$, B. Stefanovic ${ }^{\mathrm{c}}$, R.D. Hoge ${ }^{\mathrm{a}, \mathrm{b}}$ \\ a Physiology/Biomedical Engineering, Université de Montréal, Montreal, Quebec, Canada \\ b CRIUGM, Montreal, Quebec, Canada \\ c Medical Biophysics, University of Toronto, Toronto, Canada
}

\section{A R T I C L E I N F O}

\section{Article history:}

Received 27 May 2010

Revised 14 September 2010

Accepted 21 September 2010

Available online 29 September 2010

\section{Keywords:}

Calibrated MRI

Carbogen

Hypercapnia

Hyperoxia

Oxygen metabolism

Venous saturation

\begin{abstract}
A B S T R A C T
Breathing a mixture of $10 \% \mathrm{CO}_{2}$ with $90 \% \mathrm{O}_{2}$ (referred to here as carbogen-10) increases blood flow due to the vasodilatory effect of $\mathrm{CO}_{2}$, and raises blood $\mathrm{O}_{2}$ saturation due to the enriched oxygen level. These effects both tend to reduce the level of deoxygenated hemoglobin in brain tissues, thereby reducing the potential for further increases in BOLD contrast. In the present study, blocks of intense visual stimulation (60 s) were presented amid longer blocks (180 s) during which subjects breathed various fractional concentrations (0-100\%) of carbogen-10 diluted with medical air. When breathing undiluted carbogen-10, the BOLD response to visual stimulation was reduced below the level of noise against the background of the carbogen-10 response. At these concentrations, the total (visual + carbogen) BOLD response amplitude $(7.5 \pm 1.0 \%, n=6)$ converged toward that seen with carbogen alone $(7.5 \pm 1.0 \%, n=6)$. In spite of the almost complete elimination of the visual BOLD response, pseudo-continuous arterial spin-labeling on a separate cohort indicated a largely preserved perfusion response $(89 \pm 34 \%, n=5)$ to the visual stimulus during inhalation of carbogen-10.

The previously discussed observations suggest that venous saturation can be driven to very high levels during carbogen inhalation, a finding which has significant implications for calibrated MRI techniques. The latter methods involve estimation of the relative change in venous $\mathrm{O}_{2}$ saturation by expressing activation-induced BOLD signal increases as a fraction of the maximal BOLD signal $M$ that would be observed as venous saturation approaches $100 \%$. While the value of $M$ has generally been extrapolated from much smaller BOLD responses induced using hypercapnia or hyperoxia, our results suggest that these effects could be combined through carbogen inhalation to obtain estimates of $M$ based on larger BOLD increases. Using a hybrid BOLD calibration model taking into account changes in both blood flow and arterial oxygenation, we estimated that inhalation of carbogen-10 led to an average venous saturation of $91 \%$, allowing us to compute an estimated $M$ value of $9.5 \%$.

(C) 2010 Elsevier Inc. All rights reserved.
\end{abstract}

\section{Introduction}

During increased brain activity, BOLD contrast in functional MRI reflects a reduction in deoxygenated hemoglobin $(\mathrm{dHb})$ concentration in the venous circulation local to the activated region. This reduction is caused by an increase in the local arterial blood flow, which is generally sufficient to increase the mean $\mathrm{O}_{2}$ saturation along the capillary bed, supporting, according to the oxygen limitation model (Buxton and Frank, 1997), an increase in delivery of $\mathrm{O}_{2}$ to neural tissues under diffusion limited conditions. In principle, the BOLD signal increase observed during a particular event carries information about the change in venous $\mathrm{dHb}$ concentration. Since virtually all $\mathrm{dHb}$ in the venous circulation of healthy individuals is generated as a result of metabolic $\mathrm{O}_{2}$ extraction, then the relative change in venous $\mathrm{dHb}$ level during stimulation should depend partly on the relative change

\footnotetext{
* Corresponding author. 4565 Queen Mary, M6803, Montreal, Qc, Canada H3W 1W5. Fax: +1 5143403548 .

E-mail address: claudine.gauthier@umontreal.ca (C.J. Gauthier).
}

in the cerebral metabolic rate of $\mathrm{O}_{2}$ consumption, or $\mathrm{CMRO}_{2}$ (Buxton and Frank, 1997). If the changes in blood flow and volume can be factored out, then in theory it should be possible to obtain a quantitative estimate of the fractional change in $\mathrm{CMRO}_{2}$ that occurred as a result of stimulation. Although the latter notion is indeed the foundation for various MRI-based methods for $\mathrm{CMRO}_{2}$ estimation (Chiarelli et al., 2007b; Davis et al., 1998), the BOLD signal change observed during activation is not itself sufficient to determine the relative change in venous $\mathrm{dHb}$ concentration. Such a determination requires expressing the activation-induced BOLD response as a fraction of the maximum possible BOLD signal increase that would be observed upon complete elimination of all $\mathrm{dHb}$ from tissues (usually denoted $M$ in literature). For this reason, various calibration methods have been proposed in which the total attenuation of $\mathrm{T}_{2}$ weighted signal attributable to $\mathrm{dHb}$ at baseline (conversely equivalent to the maximum possible BOLD signal increase) is estimated through extrapolation of BOLD signal increases observed during mild hypercapnia (Davis et al., 1998) or hyperoxia (Chiarelli et al., 2007b). In the hypercapnia method, $M$ is extrapolated from the 
BOLD and flow responses during mild hypercapnia (typically achieved by having subjects breathe $5-10 \% \mathrm{CO}_{2}$ in air). This is the earliest calibration method introduced by Davis et al. and has since been employed in numerous studies (Ances et al., 2008, 2009; Bulte et al., 2009; Chen and Parrish, 2009; Davis et al., 1998; Hoge et al., 1999b; Leontiev et al., 2007; Lin et al., 2008; Perthen et al., 2008; Stefanovic et al., 2006). In the more recently introduced hyperoxia calibration method, a similar model is used to estimate $M$ from the BOLD response to hyperoxia (usually induced through inhalation of 50$100 \% \mathrm{O}_{2}$ ). This model uses end-tidal $\mathrm{PO}_{2}$ (partial pressure of oxygen) values to estimate the venous deoxygenated hemoglobin fraction, with the additional assumption of an unchanged CBF in the case of mild hyperoxia or of a fixed, pre-determined CBF decrease in the case of higher inspired $\mathrm{O}_{2}$ concentrations (Chiarelli et al., 2007b; Goodwin et al., 2009).

Because of the uncertainties inherent when resorting to extrapolation, as well as some speculative aspects of the BOLD signal models applied, the validity of such calibration methods has been difficult to confirm (Ances et al., 2008; Buxton et al., 2004; Chen and Pike, 2010; Chiarelli et al., 2007a; Hoge et al., 1999a,b; Hoge and Pike, 2001; Stefanovic et al., 2006; Zappe et al., 2008). Previous studies using hypercapnia or hyperoxia have reported $M$ values ranging from 3.7 to $22 \%$. An important consideration when comparing such data is that the measured value is specific not only to a particular anatomic region, but also to the applicable measurement conditions, including field strength, echo time, and the degree of vascular weighting (use of diffusion crusher gradients, prevalence of veins in ROIs). Since the parameter $M$ is, implicitly, a linear function of the echo time used in the experiment (see Eq. (7) in Hoge et al., 1999a,), it is necessary to correct by the ratio of echo times when comparing $M$ values from different experiments. After adjustment to an equivalent echo-time of $30 \mathrm{~ms}$, percent $M$ values measured in visual cortex at $1.5 \mathrm{~T}$ (only hypercapnic calibration has been used at this field strength) include 3.4 (Davis et al., 1998), 4.6 (Stefanovic et al., 2006), and 13.2 (Hoge et al., 1999a,b). Hypercapnically determined visual cortex $M$ values at $3 \mathrm{~T}$, adjusted to a common TE of $30 \mathrm{~ms}$, include 5.3 (Bulte et al., 2009), 5.7 (Ances et al., 2008), 6.5 and 7.3 (Ances et al., 2009), 6.7 (Chen and Parrish, 2009), 10.5 (Lin et al., 2008), 11.1 (Leontiev et al., 2007) and 11.6 and 12.1 (Perthen et al., 2008) for hypercapnia. A value of $7.0 \%$ was measured by Chiarelli et al. in visual cortex at $3 \mathrm{~T}(\mathrm{TE}=30 \mathrm{~ms})$ using hyperoxic calibration (Chiarelli et al., 2007b). While some of the variability in reported $M$ values may reflect differences in venous weighting associated with the ROI selection or other factors, it is also clear that the majority of estimated $M$ values represent BOLD signal increases that are considerably higher than those typically measured during even the most intense stimulation paradigms. Although this is to be expected in a value that is supposed to represent the maximum possible signal increase, the veracity of such large signal changes has been understandably questioned (Chiarelli et al., 2007a,b) given their basis in extrapolation via biophysical models which unavoidably include a certain degree of speculation. Methods in which hypercapnia is used may further suffer from the low-signal-to-noise ratio of arterial spin-labeling measures needed to measure flow changes during this type of calibration. Use of an appropriate $M$ value is critical in calibrated MRI, as incorrect values can lead to substantial bias in estimated $\mathrm{CMRO}_{2}$ values as well as in apparent $\mathrm{CBF}-\mathrm{CMRO}_{2}$ coupling relations, as has been pointed out by Chiarelli et al. (2007a).

If a method could be devised to raise the venous $\mathrm{O}_{2}$ saturation close to $100 \%$, then the maximum achievable BOLD signal could be determined more directly for a given physiological baseline state. The objective of the present study was therefore to explore the use of a breathing gas mixture consisting of $10 \%$ carbon dioxide and $90 \%$ oxygen (referred to here as carbogen-10 since the term carbogen alone is used to describe any mixture of $\mathrm{CO}_{2}$ with balance $100 \% \mathrm{O}_{2}$ ) as a means of producing very high levels of venous $\mathrm{O}_{2}$ saturation. Hypercapnia, induced using carbon dioxide concentrations of 4 to
$10 \%$, has been explored extensively in the past as a means of producing robust BOLD signals due to the vasodilatory action of $\mathrm{CO}_{2}$ (Kim et al., 1999; Kemna et al. 2001; Posse et al. 2001; Stefanovic et al., 2006; Chiarelli et al., 2007a; Leontiev and Buxton, 2007; Leontiev et al., 2007; Ances et al., 2008, 2009; Perthen et al., 2008; Bulte et al., 2009; Chen and Parrish, 2009; Mark et al., 2010), and carbogen has been explored to evaluate susceptibility-weighted imaging methods and in the study of tumor oxygenation (Ashkanian et al., 2008, 2009; Dunn et al., 2002; Landuyt et al., 2001; Rauscher et al., 2005b; Sedlacik et al., 2008; van der Sanden et al., 1999). The use of a relatively high $\mathrm{CO}_{2}$ content (10\%) combined with enrichment of $\mathrm{O}_{2}$ (90\% as opposed to $21 \%$ in atmospheric composition air) should lead to very high venous $\mathrm{O}_{2}$ saturations (Bulte et al., 2009; Ogawa et al., 1990; Rauscher et al., 2006; Sedlacik et al., 2008). To further increase venous $\mathrm{O}_{2}$ in specific cortical areas, and to assess the degree to which BOLD reactivity approaches saturation against a background of very high venous saturation, we applied intense visual stimulation during periods of carbogen-10 inhalation. Titration studies in which subjects breathed various concentrations of carbogen-10 in air, with and without intense visual stimulation, suggested that inhalation of pure carbogen-10 results in almost complete elimination of venous $\mathrm{dHb}$ in visual cortex and thus allows a more direct estimation of the asymptotic BOLD signal increase $M$.

\section{Methods}

Acquisitions were conducted in nine healthy subjects, seven males and two females, aged 21 to 32 years, on a Siemens TIM Trio 3 T MRI system (Siemens Medical Solutions, Erlangen, Germany) using the Siemens 32-channel receive-only head coil for all acquisitions. All subjects gave informed consent and the project was approved by the Comité mixte d'éthique de la recherche du Regroupement Neuroimagerie/Québec. Two types of scanning session were performed, each on a subset of six of the nine subjects. The first type of session consisted of the BOLD titration experiments in which varying fractions of carbogen-10 were administered either with or without simultaneous visual stimulation. The second session type focused on perfusion imaging with pseudo-continuous arterial spin-labeling (pCASL) during combined carbogen inhalation and visual stimulation.

BOLD titration sessions included an anatomical, $1 \mathrm{~mm}^{3}$ MPRAGE acquisition (TR/TE/alpha $=2300 \mathrm{~ms} / 3 \mathrm{~ms} / 9^{\circ}, 256 \times 240$ matrix) and nine BOLD functional runs (TR/TE/alpha $=2000 \mathrm{~ms} / 30 \mathrm{~ms} / 90^{\circ}$ with $4 \times 4 \times 4 \mathrm{~mm}$ voxels, $64 \times 64$ matrix and 33 slices). During these BOLD acquisitions, subjects underwent a titration of carbogen-10 $\left(10 \% \mathrm{CO}_{2}\right.$ and $90 \% \mathrm{O}_{2}$ ) (Vitalaire Santé, Montreal, QC, Canada). Two runs of each of the four carbogen fractions (25\%,50\%, $75 \%$ and $100 \%$ ) with balance air were performed (see Table 1 for gas concentrations associated with each fraction). For each fraction, one run was conducted with a single three-minute carbogen block, after an initial $90 \mathrm{~s}$ of air breathing (all percent change values in this report are expressed relative to the airbreathing baseline). A second run was performed for each carbogen/air fraction with the addition of a 1-min block of visual stimulation. The visual stimulus was a black and white radial checkerboard, annuli scaled logarithmically with eccentricity, luminance modulated in a temporal squarewave at $8 \mathrm{~Hz}$ (equivalent to 16 contrast reversals per second)

Table 1

Gas mixture compositions. Concentration of each component gas of the mixtures administered to the subjects in the course of this titration experiment.

\begin{tabular}{llll}
\hline & $\% \mathrm{CO}_{2}$ & $\% \mathrm{O}_{2}$ & $\% \mathrm{~N}_{2}$ \\
\hline Medical air & 0 & 21 & 79 \\
$25 \%$ carbogen-10 & 2.5 & 38.25 & 59.25 \\
$50 \%$ carbogen-10 & 5 & 55.5 & 39.5 \\
$75 \%$ carbogen-10 & 7.5 & 72.75 & 19.75 \\
$100 \%$ carbogen-10 & 10 & 90 & 0 \\
\hline
\end{tabular}


presented using a LCD projector (EMP-8300, Epson, Toronto, ON, Canada) onto a translucent screen viewed by subjects through a mirror integrated into the Siemens head coil. This stimulation was initiated $90 \mathrm{~s}$ into the carbogen block (actual run order was randomized). An additional run was done with the visual stimulus presented without carbogen, with the stimulus starting $180 \mathrm{~s}$ into the run as in the other acquisitions.

Additional acquisitions were performed on some subjects. In one subject, two susceptibility-weighted images (SWI) (Rauscher et al., 2005a; Reichenbach and Haacke, 2001) were obtained to provide a qualitative assessment of the venous oxygenation increase with carbogen. One image was acquired during medical air breathing and one during carbogen-10 inhalation. The image obtained during carbogen breathing was acquired after an initial 1-min period of carbogen breathing to allow oxygen saturation and vasodilation to reach a plateau. Parameters used for the SWI acquisition were: TR/TE/ alpha $=27 \mathrm{~ms} / 20 \mathrm{~ms} / 15^{\circ}$ with $0.9 \times 0.9 \mathrm{~mm}$ in-plane resolution with 56 slices of $1.5 \mathrm{~mm}$ on a $256 \times 192$ matrix.

To determine the effect of carbogen more specifically on the visually evoked perfusion response, a pseudo-continuous arterial spin labeling (pCASL) acquisition (Wu et al., 2007) was used to measure changes in cerebral blood flow (CBF) in six subjects during combined carbogen-10 inhalation and visual stimulation. The data from one subject could not be used due to excessive movement. The same experimental timing and visual paradigm was used to deliver carbogen-10 during this acquisition. The parameters used in the pCASL sequence were: TR/TE/ alpha $=3000 \mathrm{~ms} / 10 \mathrm{~ms} / 90^{\circ}$ with $4 \times 4 \mathrm{~mm}$ in-plane resolution and 16 slices of $6 \mathrm{~mm}$ ( $1 \mathrm{~mm}$ slice gap) on a $64 \times 64$ matrix (at 7/8 partial Fourier), GRAPPA acceleration factor $=2$ (Griswold et al., 2002), postlabeling delay $=900 \mathrm{~ms}$, Hanning window-shaped RF pulse with duration $/$ space $=500 \mu \mathrm{s} / 920 \mu \mathrm{s}$, flip angle of labeling pulse $=25^{\circ}$, slice-selective gradient $=6 \mathrm{mT} / \mathrm{m}$, tagging duration $=2 \mathrm{~s}$ (Wu et al., 2007).

\section{Gas manipulations}

At the beginning of the experiment, subjects were fitted with a non-rebreathing face mask (Hudson RCI, \#1059, Temecula, California, USA). To avoid discomfort from outward gas leakage blowing into the subject's eyes, skin tape (Tegaderm Film, \#1626W, 3M Health Care, St-Paul, MN, USA) was used to seal the top of the mask to the face. Plastic tubing (Airlife ${ }^{\mathrm{TM}}$ Oxygen tubing \#001305, Cardinal Health, McGraw Park, IL, USA) and a Y-connector were used to connect pressure/flow-meters for medical air and carbogen-10 tanks (Vitalaire, Missisauga, ON, Canada) to the mask. Gas flows were adjusted manually on the pressure/flow-meters (MEGS, Ville StLaurent, QC, Canada) to keep a total flow rate of $16 \mathrm{~L} / \mathrm{min}$. Gas flow was kept at $16 \mathrm{~L} / \mathrm{min}$ at all times except during administration of the highest carbogen concentration. From the control room, the reservoir bag affixed to the non-rebreathing mask could be seen. For subjects found to hyperventilate beyond the gas delivery used in the other acquisitions (causing the reservoir bag to collapse fully at the end of each breath and some atmospheric air to be entrained into the mask), gas flow rates were increased to the maximal possible rate ( $25 \mathrm{~L} / \mathrm{min}$ ) achievable with our pressure/flowmeters for the highest carbogen-10 concentration acquisitions. Pulse rate and arterial $\mathrm{O}_{2}$ saturation were monitored in all subjects using a pulse-oximeter (InVivo Instruments, Orlando, USA) as a safety measure and to observe the effects of carbogen breathing.

End-tidal $\mathrm{O}_{2}$ and $\mathrm{CO}_{2}$ values were monitored in five subjects. Gases were sampled via an indwelling nasal cannula (Airlife ${ }^{\mathrm{TM}}$ Nasal Oxygen Cannula \#001321, Cardinal Health, McGraw Park, IL, USA) using the CO2100C and O2100C modules of the MP150 BIOPAC physiological monitoring unit (BIOPAC Systems Inc., Goleta, CA, USA). Calibration of the unit was done by taking into account an expired partial pressure of water of $47 \mathrm{mmHg}$ (Severinghaus, 1989). Subjects were instructed to breathe through their nose, which ensured that only expired gas was sampled by the nasal cannula.

Following acquisition, all subjects were debriefed to assess the level of discomfort associated with the manipulation. The subjects were asked to rate the air hunger and breathing discomfort associated with the maximal carbogen-10 concentration on a French language version of the scale proposed by Banzett et al. (1996). Subjects were asked to rate the discomfort of the carbogen-breathing block in three parts: the first half of the block, the second half, and over the whole manipulation.

\section{Data analysis}

All MRI data were analyzed using the Neurolens data analysis software package (www.neurolens.org). BOLD data were motion corrected (Cox and Jesmanowicz, 1999) and spatially smoothed with a $6 \mathrm{~mm}$ 3D Gaussian kernel. ASL data were similarly processed, and the CBF signal was isolated through surround subtraction using linear interpolation between neighboring points (Liu and Wong, 2005). A general linear model (GLM) assuming a hemodynamic response function (HRF) consisting of a single gamma function (Glover, 1999) and a linear drift and constant offset terms was applied, to obtain effect sizes and T-maps for each condition (visual and/or carbogen). The first $60 \mathrm{~s}$ after gas transitions were excluded from the analyses by zeroing out relevant matrix rows in the GLM computation, as the transition periods would not be accurately modeled by the HRF used in the GLM fit (as can be appreciated from Fig. 3).

Regions of interest (ROIs) were derived from thresholded ( $p \leq 0.01$ corrected) (Worsley et al., 2002) visual activation T-maps (Fig. 1). Fractional changes were then calculated by dividing effect sizes over the visual ROI by the constant DC term from the GLM averaged within the region. Group average values \pm standard error are reported here. Time courses were obtained by averaging the fractional signal change traces for five subjects at each carbogen concentration. The linear trend and DC terms from the full linear model were removed from the pre-processed ROI-average signal traces of each subject before averaging signal traces (converted to percent change) between subjects. One subject was excluded from this analysis because of a missing acquisition for one carbogen concentration. Separate visual ROIs were made for ASL acquisitions with the same statistical $(p=0.01)$ threshold as for BOLD acquisitions.

To estimate the incremental response due to visual stimulation against the background of carbogen-10 breathing in BOLD and CBF signals, a linear model was fit to the group average time course for the respective signals (BOLD and ASL, expressed as percent change) for the visual stimulation + carbogen experiment. For the BOLD signal, the regressors consisted of a carbogen response term based on the group average data (after de-trending and normalization) for carbogen alone, plus a 60 second square pulse representing the visual response term. Other GLM parameters (HRF, etc.) were as described previously.

End-tidal $\mathrm{CO}_{2}$ and $\mathrm{O}_{2}$ values were picked manually and averaged over all subjects, for the first five breaths of the experiment, when subjects were breathing air, and for the last ten breaths of the carbogen-10 breathing block.

Arterial spin-labeling measurements acquired during carbogen inhalation were corrected for T1 changes using the approach described in (Chalela et al., 2000; Zaharchuk et al., 2008). Arterial blood T1 values of $1660 \mathrm{~ms}$ and $1487 \mathrm{~ms}$ were used, respectively, for normoxia and the hyperoxic state produced by carbogen-10 (from T1 vs. $\mathrm{Fi}_{\mathrm{O} 2}$ values tabulated in Bulte et al. (2007). Since the T1 depends specifically on the level of dissolved $\mathrm{O}_{2}$ in the plasma, and since we obtained different $\mathrm{Pa}_{\mathrm{O} 2}$ (arterial partial pressure of $\mathrm{O}_{2}$ ) values at a given $\mathrm{Fi}_{\mathrm{O} 2}$ (fraction of inspired $\mathrm{O}_{2}$ ) than the latter study (their $\mathrm{Pa}_{\mathrm{O} 2}$ values were higher, likely due to the use of a tightly sealed face mask), the values were interpolated to account for this difference (i.e. the 


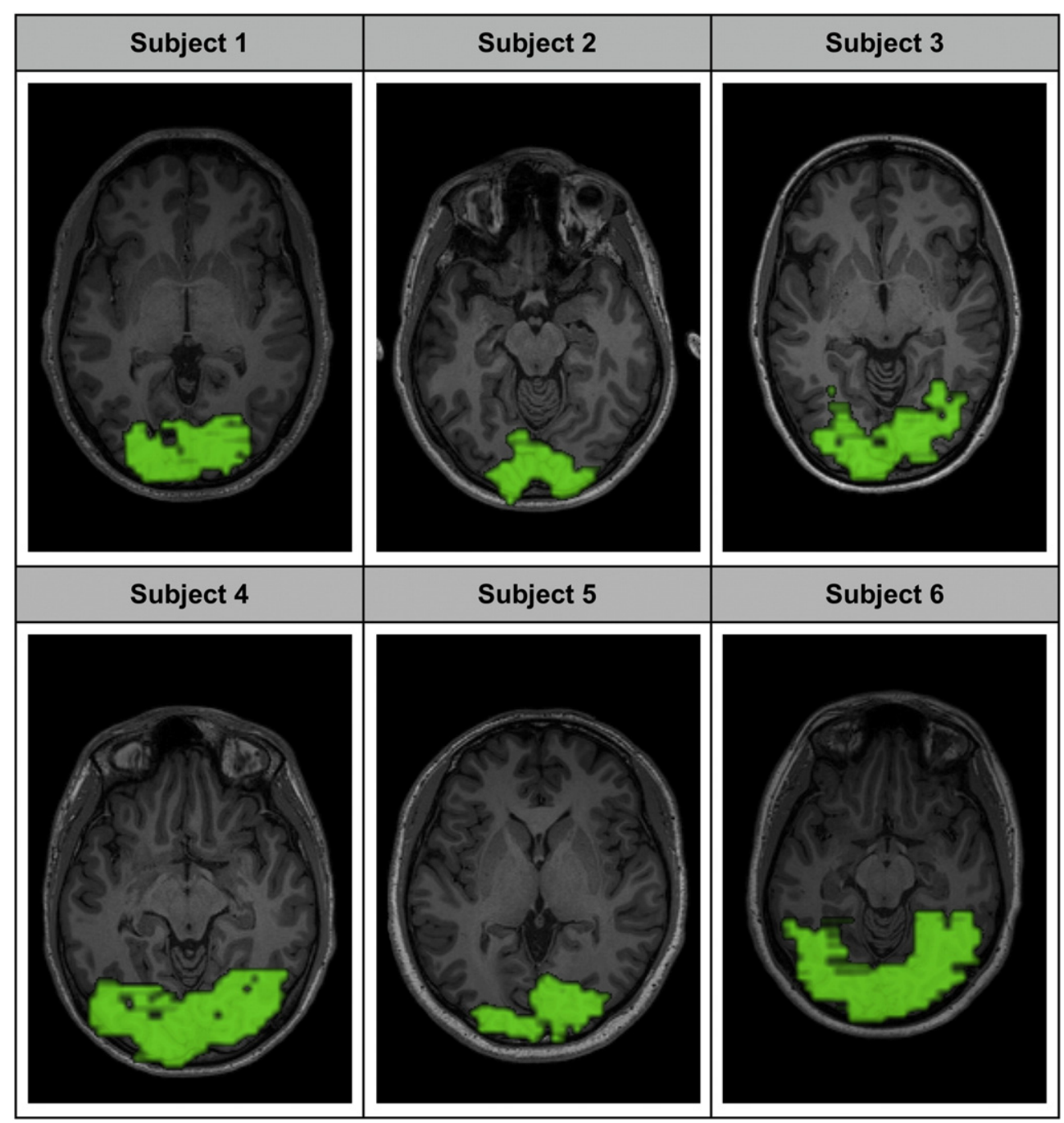

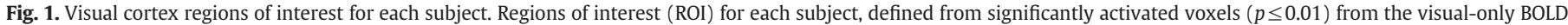
acquisition of each subject. This procedure yielded diffuse ROIs over visual areas.

table from Bulte was converted to T1 vs. group average $\mathrm{Pa}_{\mathrm{O} 2}$, and the $\mathrm{T} 1$ corresponding to our group average $\mathrm{Pa}_{\mathrm{O} 2}$ during inhalation of carbogen-10 was interpolated). The $\mathrm{T} 1$ correction factor was thus determined to be 1.07 (i.e. flow would be underestimated by $7 \%$ without correction). Values for the absolute blood flow at the airbreathing baseline were computed using Eq. (1) from Wang et al. (2003), assuming the same constant values as in this reference.

\section{Results}

Visual stimulation alone resulted in extensive BOLD activation throughout visual cortex, as shown in ROI masks in Fig. 1. Inhalation of carbogen-10 caused large BOLD signal increases in cortical and subcortical grey matter (Fig. 2), with the incremental contribution from the addition of visual stimulation becoming successively smaller at higher fractional carbogen concentrations (Figs. 3 and 5). Percent changes for both stimuli (carbogen-10 alone and carbogen-10 + visual) averaged over visually activated areas in individual subjects show a universal tendency to converge towards a common maximal signal change (Fig. 4). Group average response curves for carbogen-10 inhalation alone and carbogen-10 plus visual stimulation show an apparent convergence of response amplitudes at the highest carbogen fractions (Fig. 5).Unpaired two-tailed $t$-tests on ROI group averages for each level, comparing with and without visual stimulation, reveal a decreasing significance level of the difference with increasing carbogen fraction ( $p=0.002$ at $25 \%$ carbogen- 10 to $p=0.96$ at $100 \%$ carbogen-10). The average percent signal change over subjects was $7.5 \% \pm 1.0$ in visual cortex for carbogen-10 inhalation alone. This was equal within measurement error to the average signal change of $7.5 \% \pm 1.0$ for carbogen-10 breathing combined with intense visual stimulation (Figs. 3 and 5). The visually evoked BOLD signal change of $2.0 \pm 0.1 \%$ measured during visual stimulation alone (i.e. breathing air) was thus largely eliminated against the carbogen background. Pulse oximetry showed a tendency for arterial $\mathrm{O}_{2}$ saturation to rise from baseline levels (typically $98 \%$ ) toward $100 \%$ in all subjects.

Due to technical limitations, end-tidal $\mathrm{O}_{2}$ and $\mathrm{CO}_{2}$ values were only acquired on a subset of five subjects during carbogen-10 inhalation. Average baseline end-tidal values were $44.4 \pm 1.1 \mathrm{mmHg}$ for $\mathrm{CO}_{2}$ and $120.0 \pm 3.8 \mathrm{mmHg}$ for $\mathrm{O}_{2}$. The group average end-tidal values during the last ten breaths of carbogen-10 inhalation were $59.2 \pm 2.4 \mathrm{mmHg}$ for $\mathrm{CO}_{2}$ and $387.9 \pm 34.1 \mathrm{mmHg}$ for $\mathrm{O}_{2}$.

\section{Additional tests}

SWI data acquired in one subject during air and carbogen-10 breathing demonstrated an almost complete loss of venous contrast 


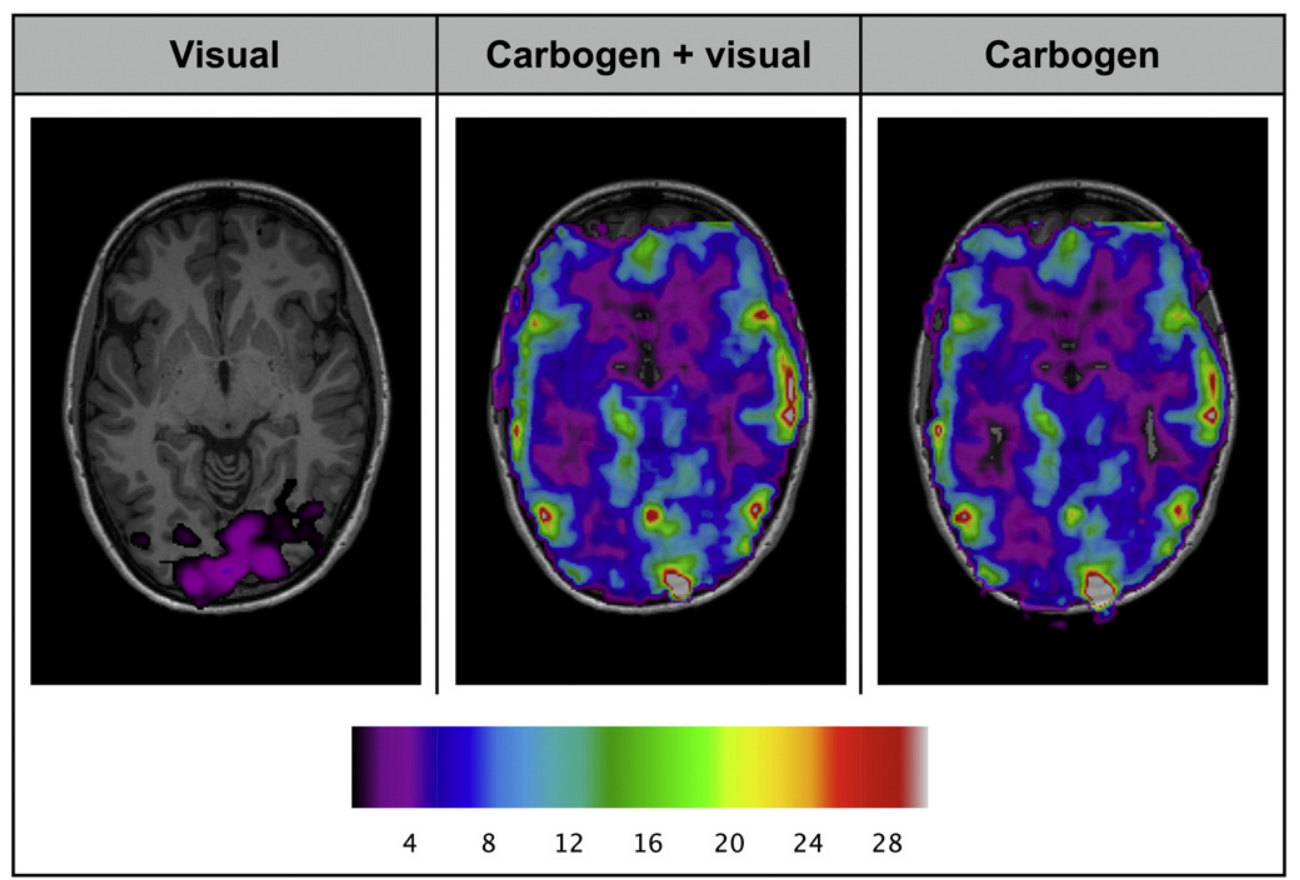

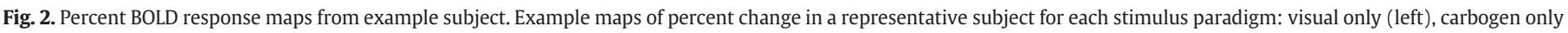

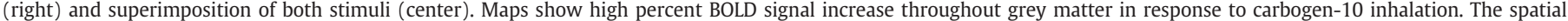

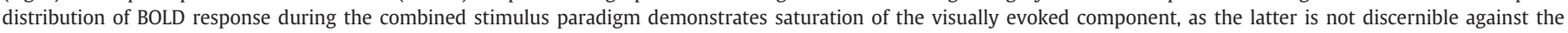
background of carbogen response.

during carbogen-10 breathing (Fig. 6). Analysis of ASL data acquired in five subjects revealed a substantial visually induced flow increase $(88.9 \pm 34.2 \%)$ against the background of carbogen inhalation, in spite of the greatly reduced visual BOLD response under similar conditions (Fig. 7). The group average flow increase from carbogen10 inhalation was $104.5 \pm 24.0 \%$ from an absolute baseline of $51.4 \pm$ $7.0 \mathrm{ml} / 100 \mathrm{~g} / \mathrm{min}$.

\section{Subjective discomfort rating}

Subjects reported a moderate to high degree of discomfort from carbogen-10 breathing. All subjects reported sensations of air hunger and hot flushes (a generalized feeling of warmth) during carbogen inhalation, which increased progressively over time during the carbogen block. All subjects included in this study had prior experience as MRI volunteers and most had already participated in at least one study including hypercapnia. Subjects were briefed extensively on the importance of reporting discomfort and reminded regularly that the experiment could be stopped immediately at their discretion if it became too uncomfortable. Two subjects asked to interrupt the experiment to request a higher gas flow rate during the highest carbogen concentration. Increasing the flow rate of carbogen beyond $16 \mathrm{~L} / \mathrm{min}$ for subjects reporting a difficulty breathing relieved much of the discomfort and allowed them to complete the experiment (illustrating the subjective nature of air hunger and complex interplay between $\mathrm{CO}_{2}$ level and ventilation parameters (Lansing et al., 2009)). Average discomfort ratings were $4.7 \pm 0.5$ out of a possible of 7 for the whole block, with all subjects reporting a discomfort rating one to two points higher for the second half of the carbogen-inhalation block, as compared to the first half.

\section{Discussion}

The diminishing incremental response from visual stimulation at high carbogen concentrations suggests that the BOLD signal obtained with this manipulation approaches the saturation plateau $M$. We observed a convergence of percent signal changes towards a common value of $7.5 \pm 1.0 \%$ for both carbogen-10 inhalation alone and combined with intense visual stimulation (Figs. 3 and 5). This saturation effect was found to be robust and was observed in all individual subjects data (Fig. 4). While investigation of the visually evoked BOLD component against a varying background of carbogen inhalation was the primary objective of this study, additional measures were also performed to elucidate the mechanisms of the observed behavior. These ancillary measures are discussed later.

\section{Arterial spin-labeling}

Analysis of pseudo-continuous arterial spin labeling data acquired in five subjects confirms that the saturation effect observed in the BOLD signal response to carbogen-10 does not arise from a reduction of the perfusion response to the visual stimulus against the carbogen background. The signal time courses averaged over the visually activated areas of both subjects show a substantial perfusion increase in response to visual stimulation $(88.9 \pm 34.2 \%)$ that is distinctly visible against the superimposed flow response to carbogen (Fig. 7B). This is in spite of the striking abolition of virtually any apparent visual contribution in the BOLD signal (Fig. 7A), and the profound tissue hyperoxia that must exist under this condition (further confirmation that activation-induced perfusion increases are unlikely to be triggered by decreased tissue $\mathrm{pO}_{2}$ during activation).

It should be noted that two competing effects represent potential confounds to flow quantification in the ASL acquisitions: T1 lengthening due to an increased arterial $\mathrm{O}_{2}$ saturation and $\mathrm{T} 1$ shortening due to increased plasma $\mathrm{O}_{2}$ concentration (Bulte et al., 2007; Buxton et al., 1998). Because we expect T1 shortening to be the predominant effect (Bulte et al., 2007, 2009), this should result in the underestimation of blood flow changes during carbogen inhalation. The effects of T1 shortening were therefore taken into account here according to the signal formulation for continuous ASL (Chalela et al., 2000; Zaharchuk 
A

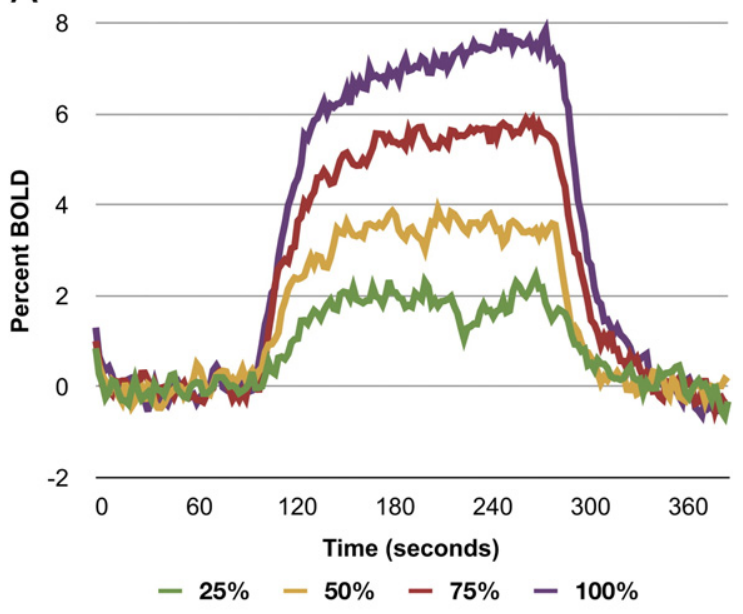

B

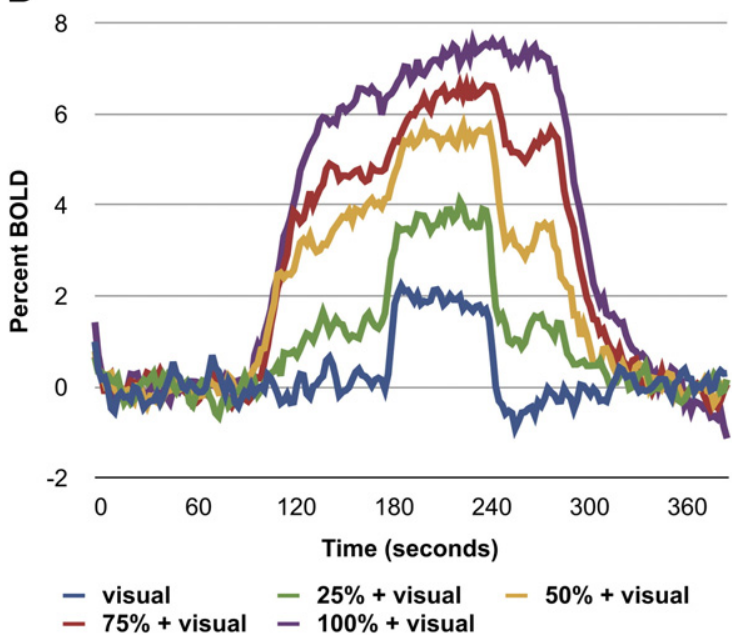

Fig. 3. BOLD Time course for carbogen inhalation and carbogen + visual stimulation. Average over five subjects of BOLD time course in visual cortex ROI during carbogen-10 inhalation alone (A) and carbogen-10 inhalation plus visual stimulation (B). This figure shows a diminishing contribution of visually evoked BOLD signal when combined with carbogen breathing. Maximal signal changes obtained with and without visual stimulation during carbogen-10 breathing are equal, within measurement error.

et al., 2008). The values for arterial blood T1 were adjusted from literature values (Bulte et al., 2007) for the $\mathrm{Pa}_{\mathrm{O} 2}$ reached in our experiments.

The perfusion increase of $104.5 \pm 24.0 \%$ measured in the present study during inhalation of carbogen-10 is similar to values found for similar end-tidal $\mathrm{P}_{\mathrm{CO} 2}$ values in previous studies using radiotracer methods (Kemna et al., 2001; Kety and Schmidt, 1948). Recent studies using pulsed ASL (PASL) have yielded smaller estimates of flow changes in response to inhalation of $10 \% \mathrm{CO}_{2}$ (Mark et al., 2010; Stefanovic et al., 2006). A number of authors have discussed the difficulty of acquiring accurate PASL measures of CBF change under conditions where the arterial transit time undergoes a large variation (such as hypercapnia) (Buxton et al., 1998; Wong et al., 1997; Yang et al., 2000). A reduced dependence of the calibration procedure on ASL measures is indeed one of the motivations for the hyperoxia method (Chiarelli et al., 2007b; Goodwin et al., 2009). We have found (in a parallel study, manuscript in preparation) that the pseudo-continuous ASL method used in the present study may avoid downward bias on flow estimates during global challenges which may be inherent in some pulsed ASL implementations due to shifts in the timing of label delivery during such manipulations (i.e. if global blood flow increases sufficiently, then the trailing edge of the tag bolus may leave the tagging region before the time TI1 at which QUIPSS 2 saturation pulses are applied (Wong et al., 1997)). This may explain the higher average flow value obtained in the present study.

\section{Susceptibility-weighted imaging}

Saturation of BOLD signal with carbogen-10 inhalation is demonstrated by the marked loss of venous contrast in SWI data acquired during carbogen-10 inhalation, when compared to data acquired during air breathing in the single subject thus studied (Fig. 6). Carbogen-5 $\left(5 \% \mathrm{CO}_{2}\right.$ and $\left.05 \% \mathrm{O}_{2}\right)$ inhalation has been shown before to lead to an almost complete loss of susceptibility contrast in SWI (susceptibility-weighted imaging) images (Rauscher et al., 2005b; Sedlacik et al., 2008, 2007, 2009). Sedlacik et al. have used SWI to quantify venous oxygenation in response to carbogen breathing in both a single vessel and whole brain approach (Sedlacik et al., 2008, 2007, 2009). The linear relationship between the $\mathrm{CO}_{2}$ content of carbogen and venous oxygenation observed by this group predicts a complete $\mathrm{O}_{2}$ saturation at around $6.3 \% \mathrm{CO}_{2}$ content of carbogen (Sedlacik et al., 2008), well below the $10 \% \mathrm{CO}_{2}$ concentration used here (although the latter study used a continuous positive airway pressure system, which may be more efficient at raising saturation at a given fraction of inspired $\mathrm{CO}_{2}$ ).

\section{Implications for calibrated MRI}

As noted in the Introduction, existing calibrated MRI methods for estimating changes in $\mathrm{CMRO}_{2}$ involve determination of the BOLD signal increase $M$ that would correspond to complete elimination of deoxygenated hemoglobin in tissues. This intermediate step has been performed in previous studies by measuring increases in cerebral blood flow and BOLD signal during hypercapnia (Davis et al., 1998) and also by measuring BOLD and end-tidal $\mathrm{O}_{2}$ changes during hyperoxia (Chiarelli et al., 2007b). The large changes in both flow and arterial oxygenation that occur during inhalation of carbogen offer the possibility of a unified calibration method that consolidates the two approaches mentioned previously. In Appendix A, we provide an example of how a modified form of the equations used in Chiarelli et al. (2007b) can be used to integrate both flow and oxygenation changes to provide an estimate of the $M$ parameter that is extrapolated from a BOLD signal increase that is much closer to the 'true' value (and thus potentially more robust). The example calculation in Appendix A is performed using our group average values for end-tidal $\mathrm{O}_{2}$ and changes in CBF and BOLD signal, since these measurements were not simultaneously acquired in all subjects (the primary focus being on saturation of visually evoked BOLD signals). Application of this modified calibration procedure to our group average data (see Appendix $\mathrm{A}$ ) indicated that venous $\mathrm{O}_{2}$ saturation rose to $91 \%$ during inhalation of carbogen-10 (from a baseline value of $70 \%$ ), and the 'true' $M$ value was extrapolated to be $9.5 \%$. If this is correct, then the BOLD signal increase measured directly during carbogen-10 breathing was $75 \%$ of the true $M$ value, which represents a considerably closer starting point for extrapolation than the measured BOLD values used in hypercapnic methods (with typical BOLD increases of 2-3\%; e.g., Ances et al., 2008, 2009; Bulte et al., 2009; Perthen et al., 2008) or hyperoxia (typical BOLD increases of 4\%; Chiarelli et al., 2007b, adjusted to TE of $30 \mathrm{~ms}$ ). The implied values for saturation and $M$ reported previously should be considered an illustrative approximation, since the input measurements were acquired at different times in cohorts which, while overlapping, were not identical. Nonetheless the calculations shown in Appendix A demonstrate a unified calibration framework that could be used to process imaging and blood gas data acquired during manipulations, such as carbogen inhalation, which change both blood flow and arterial $\mathrm{O} 2$ content.

Regardless of the approximations involved, the BOLD signal measured in response to carbogen-10 puts a lower bound of $7.5 \%$ on the possible value of $M$ in visual cortex under the conditions of our 
Subject 1

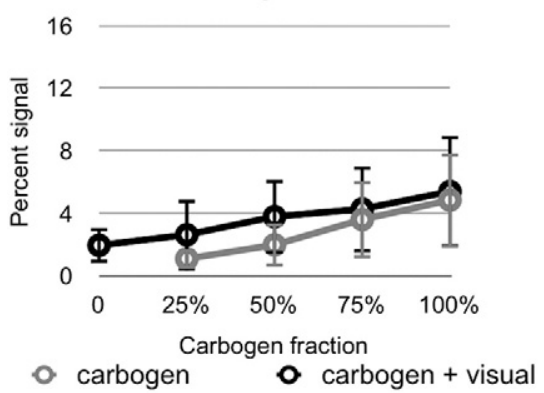

Subject 3
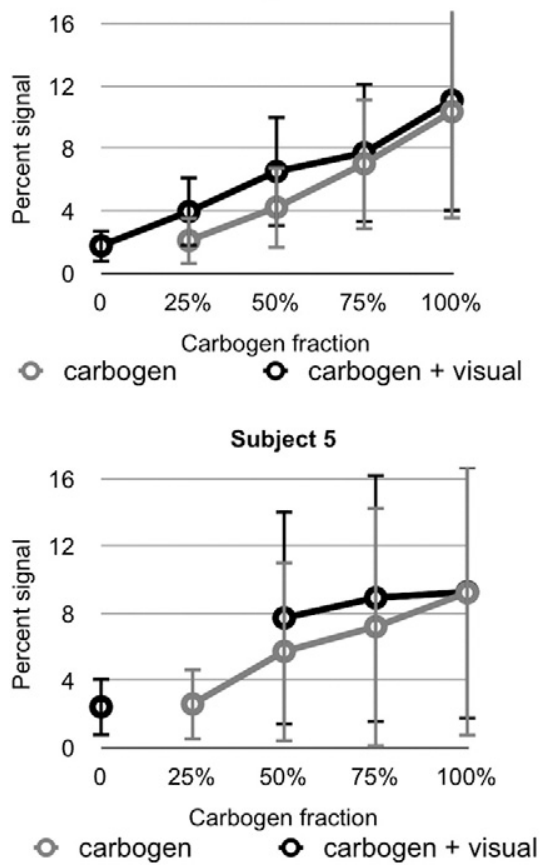

Subject 2

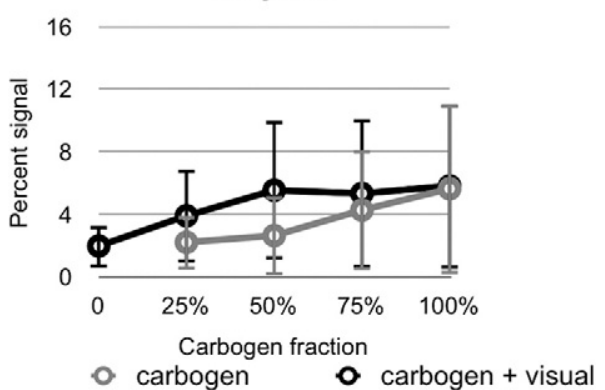

Subject 4

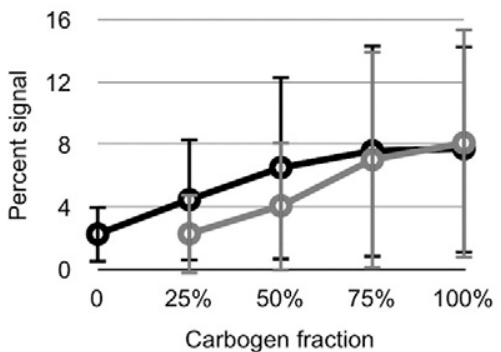

- carbogen $\quad$ carbogen + visual

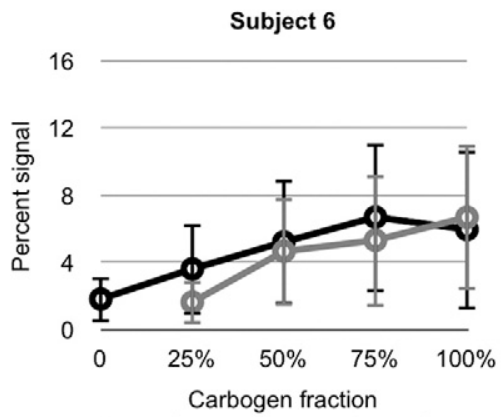

- carbogen 0 carbogen + visual

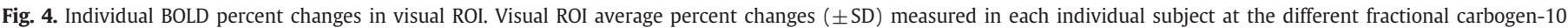

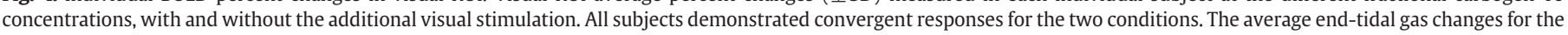
$100 \%$ carbogen-10 condition were $59.2 \pm 2.4 \mathrm{mmHg}$ for $\mathrm{CO}_{2}$ and $387.9 \pm 34.1 \mathrm{mmHg}$ for $\mathrm{O}_{2}$.

experiment $(\mathrm{TE}=30 \mathrm{~ms}, 3 \mathrm{~T})$. This is in the middle range of literature values reported for similar populations (Table 2) and adjusted to the TE used in our experiment (Ances et al., 2008, 2009; Bulte et al., 2009;

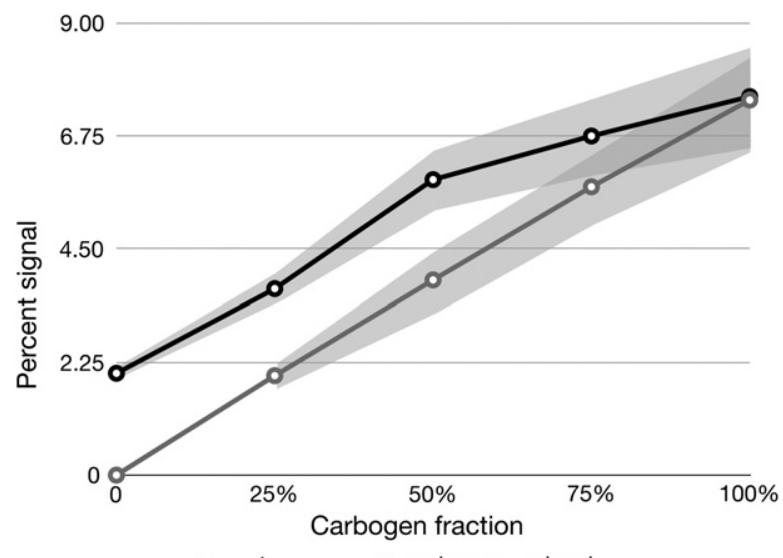

- carbogen o carbogen + visual

Fig. 5. Group-average BOLD response amplitudes. Group average percent BOLD signal change over a visual ROI (solid lines) within standard error bounds (grey shading) for each stimulus paradigm. The convergence of the two curves suggests saturation of the total BOLD response at values above $7.5 \%$.
Chen and Parrish, 2009; Leontiev and Buxton, 2007; Leontiev et al., 2007; Lin et al., 2008; Perthen et al., 2008; Stefanovic et al., 2006). Fig. 8 shows maps of the BOLD signal change measured during

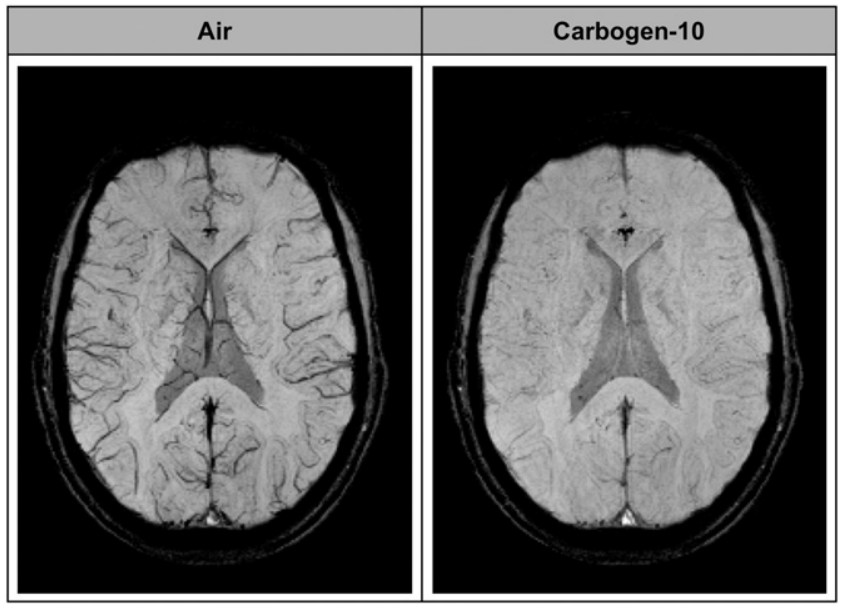

Fig. 6. Susceptibility-weighted venogram. SWI data acquired during air and carbogen-10 inhalation in a single subject. There is an almost complete loss of venous contrast during carbogen inhalation, demonstrating the high venous oxygen saturation attained. 
A

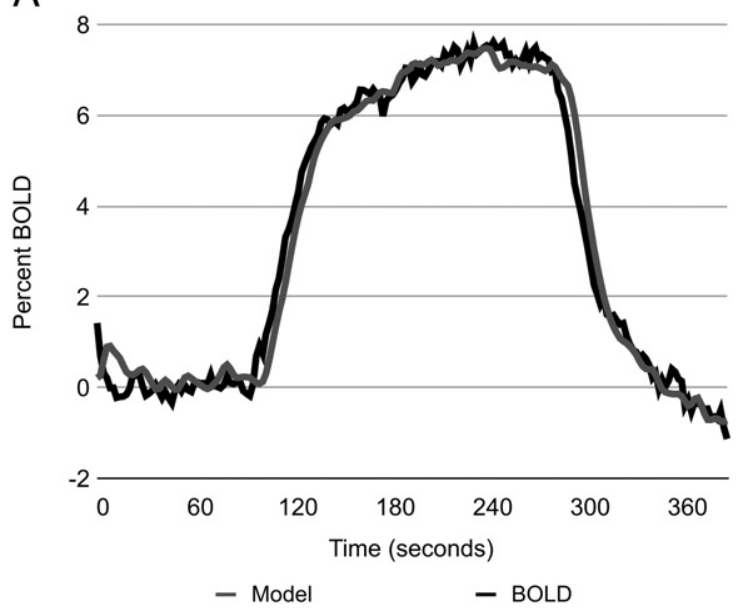

B

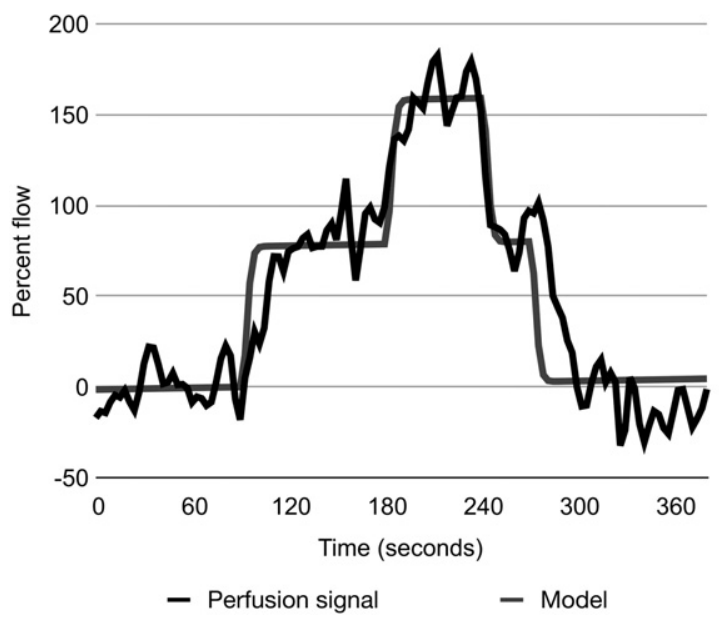

Fig. 7. BOLD and ASL time courses for visual stimulation during carbogen-10 breathing Visual ROI time-course averages (five subjects) for BOLD (A) and ASL (B). The average time courses are shown in black, along with the GLM fits in grey. Although the visually evoked BOLD response is barely detectable, the perfusion response to the visual stimulus is distinctly apparent against the background perfusion increase from breathing carbogen-10. This suggests that a largely intact visual flow response may be invoked in spite of the background hyperoxia due to carbogen-10 inhalation, and even though the BOLD response component has been all but eliminated.

inhalation of carbogen-10 for all subjects, which show clear delineation of cortical and vascular anatomy at response amplitudes are likely to be much closer to the maximum possible BOLD signal

Table 2

Literature $M$ values at $3 \mathrm{~T}$. Literature $M$ values for visual cortex from calibrated MR studies at $3 \mathrm{~T}$, adjusted to $\mathrm{TE}=30 \mathrm{~ms}$ (commonly used at $3 \mathrm{~T}$ as in the present study). $\mathrm{HC}=$ hypercapnia $\left(\mathrm{CO}_{2} /\right.$ air mixture $), \mathrm{HO}=$ hyperoxia, $\mathrm{CG}=$ carbogen $\left(\mathrm{CO}_{2} / \mathrm{O}_{2}\right.$ mixture). The $M$ value of $9.5 \%$, approximated from group average values in the current study, is in the middle range of literature values.

\begin{tabular}{llr}
\hline & Calibration technique & $M$ \\
\hline Bulte et al., 2009 & HC (4\%) & 5.3 \\
Ances et al., 2008 & HC (5\%) & 5.7 \\
Ances et al., 2009 & HC (5\%) & 6.5 \\
Chen and Parrish, 2009 & HC (5\%) & 6.7 \\
Chiarelli et al., 2007b & HO & 7.0 \\
Ances et al., 2009 & HC (5\%) & 7.3 \\
Current data & CG (10\%) & 9.5 \\
Lin et al., 2008 & HC (5\%) & 10.5 \\
Leontiev and Buxton, 2007 & HC (5\%) & 11.1 \\
Perthen et al., 2008 & HC (5\%) & 11.6 \\
& & 12.1 \\
\hline
\end{tabular}

increase than was possible with other calibration methods. Calibrated MRI maps of $\mathrm{CMRO}_{2}$ change based on such data may prove more robust, due to the reduced range of extrapolation involved in estimating the $M$ parameter.

\section{Pitfalls and future directions}

While the potential of calibrated MRI using carbogen-10 inhalation appears promising, the discomfort associated with this high level of $\mathrm{CO}_{2}$ is likely to preclude its application in frail and aging populations. This limitation is largely a question of comfort, and the procedure was found to be safely tolerated by young healthy volunteers. This is consistent with prior studies in which the safety of hypercapnia has been demonstrated at levels comparable to those used in the present study (Goode et al., 2009; Kemna and Posse, 2001; Kemna et al., 2001; Mark et al., 2010; Posse et al., 2001; Stefanovic et al., 2006). Higher levels of hypercapnia are routinely attained in clinical procedures such as permissive hypercapnia, during which end-tidal $\mathrm{CO}_{2}$ may reach $100 \mathrm{mmHg}$ without adverse effects in patients who do not have elevated intra-cranial pressure (Feihl and Perret, 1994).

Inhalation of $10 \% \mathrm{CO}_{2}$ has been used in several previous studies and these studies report only moderate degrees of discomfort from their subject. All subjects that participated in this study had previous experience as MRI subjects. Most had already taken part in hypercapnia studies and reported mild discomfort ratings on the Banzett scale to the level of hypercapnia typically used in our experiments (e.g. $5 \mathrm{mmHg}$ increase from baseline). In the experiments presented here with carbogen-10, the average air hunger rating was $4.7 \pm 0.5$ on the Banzett scale over the whole block (representing a moderate degree of discomfort) and $5.7 \pm 0.7$ during the end of the block. All subjects reported feeling a much milder degree of discomfort during the first half of the 3-min carbogen block and the two reports of extreme discomfort occurred within $10 \mathrm{~s}$ of the end of the block. This is clearly a concern when considering adoption of the carbogen-10 manipulation as a general calibration method for fMRI. It is nonetheless possible that a lower $\mathrm{CO}_{2}$ concentration (e.g. $7 \% \mathrm{CO}_{2}$ ) could be used to achieve similar results with less discomfort.

The degree of hypercapnia and hyperoxia induced in our subjects during inhalation of carbogen-10 may have been influenced by mixing of ambient air with the inspired gases. Though the mask fit well most subjects and despite the sealing of the top portion with tape, it is possible that there was some air entrained into the mask during periods of hyperventilation. However, to minimize this effect, the volume of the reservoir bag was monitored visually and gas inflow rate was adjusted to ensure that some small residual capacity remained in the bag at all times.

Alternate approaches to determine the maximal BOLD signal could include measurement of the BOLD signal produced with a combination of hyperoxia ( $100 \% \mathrm{O}_{2}$ breathing) with acetazolamide challenge. This would circumvent the discomfort of $\mathrm{CO}_{2}$ inhalation and allow a controlled investigation of the increased perfusion needed to saturate venous blood and the BOLD signal. Time domain optical measures (Gagnon et al., 2008) could also be used to investigate tissue deoxy- and oxyhemoglobin concentrations with carbogen breathing. Furthermore, animal studies in which more invasive measurements (e.g. intrinsic optical imaging on exposed cortex) and manipulations including broader blood gas manipulations using hyperbaric conditions would also allow a more thorough study of these effects.

\section{Conclusion}

Carbogen-10 breathing, through direct $\mathrm{O}_{2}$ enrichment combined with the vasodilatory action of $\mathrm{CO}_{2}$, can be used to saturate the BOLD fMRI signal to the point where the response to intense sensory stimulation is reduced below the level of measurement error (the same BOLD signal increase of 7.5\% was found during both carbogen-10 inhalation alone and during carbogen-10 plus visual stimulation). 


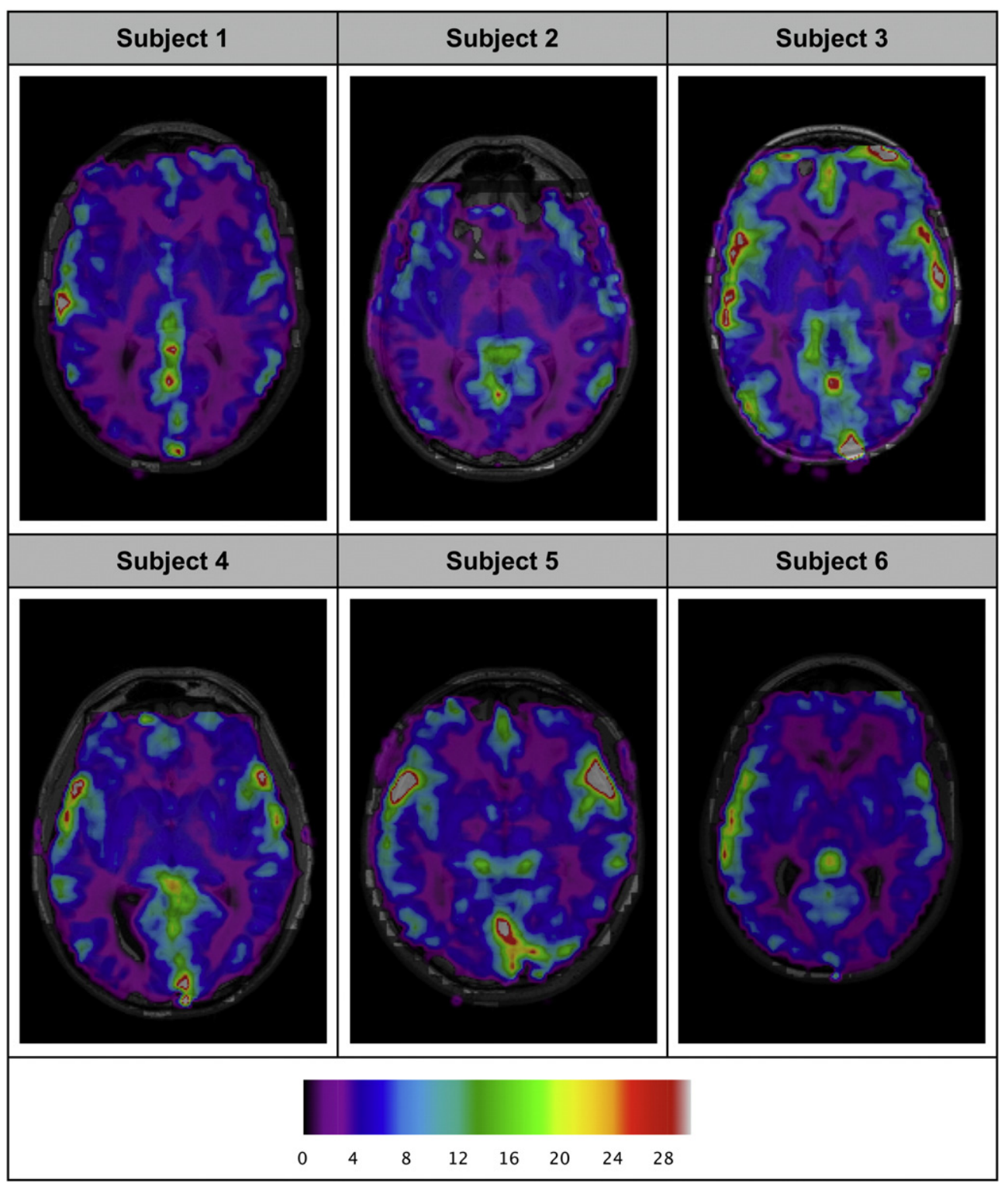

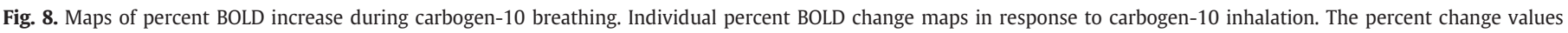
observed represent a lower bound on regional $M$ values.

These observations put a lower bound on $M$ that is in the middle range of TE-adjusted values from the literature. While the discomfort associated with the high level of $\mathrm{CO}_{2}$ employed here would rule out its application in frail or aging populations, lower concentrations may be more tolerable. The robustness of the BOLD signal measured with carbogen inhalation makes it attractive as a new option for calibrated MRI, and for validation of existing calibrated MRI methods in which $M$ is extrapolated over a larger range. We are currently carrying out more in-depth studies incorporating dual-echo pCASL and different carbogen compositions to explore the interplay between the flow and oxygenation responses under the conditions explored in the present study. These studies also aim to compare $M$ values and $\mathrm{CMRO}_{2}$ response estimates obtained using carbogen, in conjunction with the hybrid calibration model shown in Appendix A, with those determined using hypercapnia or hyperoxia.

\section{Acknowledgments}

We thank Carollyn Hurst, André Cyr and Olivia Bibollet-Bahena for help with data acquisition, as well as Clarisse Mark and Joseph Fisher for helpful discussions on respiratory physiology and Daniel Bulte for helpful discussions on gas monitoring. We would also like to thank Jiongjiong Wang, who provided the pseudo-continuous arterial spinlabeling sequence used. This work was supported by the Canadian Institutes for Health Research (MOP 84378, Banting and Best Scholarship held by CJG), the Canadian Foundation for Innovation (Leaders Opportunity Fund 17380), and the Quebec Bio-Imaging Network (Pilot Grant 5886). We would also like to thank Jean-Marc Lina and the Fonds de la Recherche sur la Nature et les Technologies for salary support provided to FBT.

\section{Appendix A}

The hyperoxia calibration method introduced by Chiarelli et al., was derived for conditions where cerebral blood flow would be expected to undergo a small decrease during hyperoxia. Eq. (12) in Chiarelli can be modified to be valid under an arbitrary change in cerebral blood flow:

$C B F \cdot C_{V_{\mathrm{O}_{2}}}=C B F \cdot C a_{\mathrm{O}_{2}}-C B F_{0} \cdot\left(\left.C a_{\mathrm{O}_{2}}\right|_{0} \cdot O E F_{0}\right)$ 
where, as in Chiarelli, CBF is the cerebral blood flow in milliliters per second, $\mathrm{Cv}_{\mathrm{O} 2}$ is the venous oxygen content in milliliters of $\mathrm{O}_{2}$ per deciliter of blood, $\mathrm{Ca}_{\mathrm{O} 2}$ is the arterial oxygen content (also in $\mathrm{ml} \mathrm{O}_{2} / \mathrm{dl}$ blood), and OEF is the oxygen extraction fraction (dimensionless, and assumed here to be 0.3 as in Chiarelli et al.). The subscript ' 0 ' is used to denote resting values for $\mathrm{Ca}_{\mathrm{O} 2}, \mathrm{OEF}$, and $\mathrm{CBF}$ (note that only the resting OEF value, which has been shown to be remarkably constant throughout the brain and across individuals (Frackowiak et al., 1980; Ito et al., 2004; Ashkanian et al., 2008; Bremmer et al., 2010; Sedlacik and Reichenbach, 2010), is required). The previously discussed expression can be easily solved for the venous $\mathrm{O}_{2}$ content during an arbitrary change in blood flow and oxygenation:

$C v_{\mathrm{O}_{2}}=C a_{\mathrm{O}_{2}}-\frac{\left(\left.C a_{\mathrm{O}_{2}}\right|_{0} \cdot O E F_{0}\right)}{\left(\frac{C B F}{C B F_{0}}\right)}$

With the previously discussed expression for $\mathrm{CV}_{\mathrm{O} 2}$, the $\mathrm{CBF}$ correction term ' $C$ ' in Eq. (8) of Chiarelli et al. can be dropped, resulting in a more explicit modeling of cerebral blood flow effects.

We can approximate the effect of increased arterial $\mathrm{O}_{2}$ content and $\mathrm{CBF}$ increase from carbogen using our group average end-tidal $\mathrm{O}_{2}$ value of $387 \pm 34 \mathrm{mmHg}$, which can be used as a surrogate for $\mathrm{Pa}_{\mathrm{O} 2}$, the arterial partial pressure of $\mathrm{O}_{2}$. We can then calculate the total arterial $\mathrm{O}_{2}$ content during carbogen-10 breathing as in Eq. (11) of Chiarelli:

$$
\begin{aligned}
C a_{\mathrm{O}_{2}}= & \left(\varphi \cdot[\mathrm{Hb}] \cdot \mathrm{Sa}_{\mathrm{O}_{2}}\right)+\left(\mathrm{Pa}_{\mathrm{O}_{2}} \cdot \varepsilon\right) \\
= & \left(1.34\left[\frac{\mathrm{ml}_{\mathrm{O}_{2}}}{\mathrm{~g}_{\mathrm{Hb}}}\right] \cdot 15\left[\frac{\mathrm{g}_{\mathrm{Hb}}}{\mathrm{dl}_{\text {blood }}}\right] \cdot 0.9996\right) \\
& +\left(387[\mathrm{mmHg}] \cdot 0.0031\left[\frac{\mathrm{ml}_{\mathrm{O}_{2}}}{\mathrm{dl}_{\text {blood }} \cdot \mathrm{mmHg}}\right]\right) \\
= & 20.09\left[\frac{\mathrm{ml}_{\mathrm{O}_{2}}}{\mathrm{dl}_{\text {blood }}}\right]+1.20\left[\frac{\mathrm{ml}_{\mathrm{O}_{2}}}{\mathrm{dl}_{\text {blood }}}\right]=21.29\left[\frac{\mathrm{ml}_{\mathrm{O}_{2}}}{\mathrm{dl}_{\text {blood }}}\right]
\end{aligned}
$$

where $\varphi$ is the $\mathrm{O}_{2}$ carrying capacity of hemoglobin, [Hb] is the concentration of hemoglobin in blood, $\mathrm{Sa}_{\mathrm{O} 2}$ is the hemoglobin saturation (estimated from our group average $\mathrm{Pa}_{\mathrm{O} 2}$ value using the Severinghaus equation as in Eq. (10) in Chiarelli et al.), and $\varepsilon$ represents the solubility of $\mathrm{O}_{2}$ in plasma. The values used are the same as those in Chiarelli et al., except for $\mathrm{Sa}_{\mathrm{O} 2}$ and $\mathrm{Pa}_{\mathrm{O} 2}$ which are based on our group average end-tidal $\mathrm{O}_{2}$ values. Units for the different quantities are indicated in square brackets. The second last line shows the relative contributions of $\mathrm{O}_{2}$ bound to $\mathrm{Hb}$ and $\mathrm{O}_{2}$ dissolved in plasma, indicating that the plasma holds approximately $6 \%$ of the total arterial $\mathrm{O}_{2}$ content during carbogen10 inhalation. At normoxia the group average arterial $\mathrm{O}_{2}$ content of hemoglobin was similar ( $19.83 \mathrm{ml} \mathrm{O}_{2} / \mathrm{dl}$ blood) but, as expected, the arterial plasma $\mathrm{O}_{2}$ content was substantially lower $\left(0.37 \mathrm{ml} \mathrm{O}_{2} / \mathrm{dl}\right.$ blood, or $2 \%$ of the total arterial $\mathrm{O}_{2}$ content) than the value obtained during inhalation of carbogen-10.

We can then proceed to estimate the venous $\mathrm{O}_{2}$ content, $\mathrm{Cv}_{\mathrm{O} 2}$, during carbogen-10 breathing, using Eq. (2):

$$
\begin{aligned}
C v_{\mathrm{O}_{2}} & =C a_{\mathrm{O}_{2}}-\frac{\left(\left.C a_{\mathrm{O}_{2}}\right|_{0} \cdot O E F_{0}\right)}{\left(\frac{C B F}{C B F_{0}}\right)} \\
& =21.29\left[\frac{\mathrm{ml}_{\mathrm{O}_{2}}}{\mathrm{dl}_{\text {blood }}}\right]-\frac{\left(20.21\left[\frac{\mathrm{ml}_{\mathrm{O}_{2}}}{\mathrm{dl}_{\text {blood }}}\right] \cdot 0.3\right)}{2.04} \\
& =18.33\left[\frac{\mathrm{ml}_{\mathrm{O}_{2}}}{\mathrm{dl}_{\text {blood }}}\right]
\end{aligned}
$$

where the value for $\left.\mathrm{Ca}_{\mathrm{O} 2}\right|_{0}$ is determined using the group average $\mathrm{Pa}_{\mathrm{O} 2}$ value at normoxia ( $120 \pm 4 \mathrm{mmHg}$ ), the $\mathrm{OEF}_{0}$ value of 0.3 is assumed from literature, and the baseline-normalized CBF value of 2.04 is the group average over five subjects who underwent carbogen-10 breathing during pCASL imaging. As expected, the venous $\mathrm{O}_{2}$ content was lower during normoxia, with a value of $14.14 \mathrm{ml} \mathrm{O}_{2} / \mathrm{dl}$ blood.

As a penultimate step, we can estimate the venous $\mathrm{O}_{2}$ saturation during breathing of carbogen-10 using Eq. (14) from Chiarelli (setting the negligible venous plasma $\mathrm{O}_{2}$ content to zero) and the $\mathrm{Cv}_{\mathrm{O} 2}$ value computed previously:

$$
S v_{\mathrm{O}_{2}}=\frac{C v_{\mathrm{O}_{2}}-\left(P_{v} / \mathrm{O}_{2} \cdot \varepsilon\right)}{\varphi \cdot[\mathrm{Hb}]}=\frac{18.33\left[\frac{\mathrm{ml}_{\mathrm{O}_{2}}}{\mathrm{dl}_{\mathrm{blood}}}\right]}{1.34\left[\frac{\mathrm{ml}_{\mathrm{O}_{2}}}{\mathrm{~g}_{\mathrm{Hb}}}\right] \cdot 15\left[\frac{\mathrm{g}_{\mathrm{Hb}}}{\mathrm{dl}_{\text {blood }}}\right]}=0.91
$$

from which it is seen that, based on group average results, the venous $\mathrm{O}_{2}$ saturation has been driven to $91 \%$ during inhalation of carbogen- 10 .

We can now estimate an $M$ value based on our group average values for $\mathrm{Sv}_{\mathrm{O} 2}$, BOLD signal increase, and $\mathrm{CBF}$ increase during inhalation of carbogen-10. With variable $\mathrm{CBF}$ incorporated explicitly in our revised expression for $\mathrm{CV}_{\mathrm{O} 2}$, we can drop the $\mathrm{CBF}$ correction term ' $C$ ' from Eq. (8) in Chiarelli, yielding:

$$
\begin{aligned}
\frac{\triangle B O L D}{B O L D_{0}} & =M\left(1-\left(\frac{C B F}{C B F_{0}}\right)^{\alpha}\left(\frac{[d H b]}{[d H b]_{0}}\right)^{\beta}\right) \\
& =M\left(1-\left(\frac{C B F}{C B F_{0}}\right)^{\alpha}\left(\frac{\left(1-S v_{02}\right)}{\left(1-\left.S v_{02}\right|_{0}\right)}\right)^{\beta}\right)
\end{aligned}
$$

where the term $\left(\mathrm{CBF} / \mathrm{CBF}_{0}\right)^{\alpha}$ is used to model cerebral blood volume, assuming $\alpha=0.38$ (Grubb et al., 1974), and $\beta=1.5$ is used to model the influence of deoxygenated hemoglobin on transverse relaxation (Boxerman et al., 1995). The previously described expression can be readily solved for $M$ :

$$
M=\frac{\frac{\Delta B O L D}{B O L D_{0}}}{1-\left(\frac{C B F}{C B F_{0}}\right)^{\alpha}\left(\frac{\left(1-S v_{02}\right)}{\left(1-\left.S v_{02}\right|_{0}\right)}\right)^{\beta}}=\frac{0.075}{1-(2.04)^{0.38}\left(\frac{(1-0.91)}{(1-0.70)}\right)^{1.5}}=0.095
$$

which indicates a true maximal BOLD signal increase of 9.5\%.

\section{References}

Ances, B.M., Leontiev, O., Perthen, J.E., Liang, C. Lansing, A.E., Buxton, R.B., 2008 Regional differences in the coupling of cerebral blood flow and oxygen metabolism changes in response to activation: implications for BOLD-fMRI. Neuroimage 39, 1510-1521.

Ances, B.M., Liang, C.L., Leontiev, O., Perthen, J.E., Fleisher, A.S., Lansing, A.E., Buxton, R.B 2009. Effects of aging on cerebral blood flow, oxygen metabolism, and blood oxygenation level dependent responses to visual stimulation. Hum. Brain Mapp. 30 1120-1132.

Ashkanian, M., Borghammer, P., Gjedde, A., Ostergaard, L., Vafaee, M., 2008. Improvement of brain tissue oxygenation by inhalation of carbogen. Neuroscience 156, 932-938.

Ashkanian, M., Gjedde, A., Mouridsen, K., Vafaee, M., Hansen, K.V., Ostergaard, L., Andersen, G., 2009. Carbogen inhalation increases oxygen transport to hypoperfused brain tissue in patients with occlusive carotid artery disease: increased oxygen transport to hypoperfused brain. Brain Res. 1304, 90-95.

Banzett, R.B., Lansing, R.W., Evans, K.C., Shea, S.A., 1996. Stimulus-response characteristics of $\mathrm{CO}_{2}$-induced air hunger in normal subjects. Respir. Physiol. 103, 19-31.

Boxerman, J.L., Hamberg, L.M., Rosen, B.R., Weisskoff, R.M., 1995. MR contrast due to intravascular magnetic susceptibility perturbations. Magn. Reson. Med. 34 555-566.

Bremmer, J.P., van Berckel, B.N., Persoon, S., Kappelle, L.J., Lammertsma, A.A., Kloet, R., Luurtsema, G., Rijbroek, A., Klijn, C.J., Boellaard, R., 2010. Day-to-day test-retest variability of $\mathrm{CBF}, \mathrm{CMRO}(2)$, and OEF measurements using dynamic (15)O PET studies. Mol. Imaging Biol. (Electronic publication ahead of print).

Bulte, D.P., Chiarelli, P.A., Wise, R.G., Jezzard, P., 2007. Cerebral perfusion response to hyperoxia. J. Cereb. Blood Flow Metab. 27, 69-75. 
Bulte, D.P., Drescher, K., Jezzard, P., 2009. Comparison of hypercapnia-based calibration techniques for measurement of cerebral oxygen metabolism with MRI. Magn. Reson. Med. 61, 391-398.

Buxton, R.B., Frank, L.R., 1997. A model for the coupling between cerebral blood flow and oxygen metabolism during neural stimulation. J. Cereb. Blood Flow Metab. 17, 64-72.

Buxton, R.B., Frank, L.R., Wong, E.C., Siewert, B., Warach, S., Edelman, R.R., 1998. A general kinetic model for quantitative perfusion imaging with arterial spin labeling. Magn. Reson. Med. 40, 383-396.

Buxton, R.B., Uludag, K., Dubowitz, D.J., Liu, T.T., 2004. Modeling the hemodynamic response to brain activation. Neuroimage 23 (Suppl 1), S220-S233.

Chalela, J.A., Alsop, D.C., Gonzalez-Atavales, J.B., Maldjian, J.A., Kasner, S.E., Detre, J.A 2000. Magnetic resonance perfusion imaging in acute ischemic stroke using continuous arterial spin labeling. Stroke 31, 680-687.

Chen, J.J., Pike, G.B., 2010. Global cerebral oxidative metabolism during hypercapnia and hypocapnia in humans: implications for BOLD fMRI. J. Cereb. Blood Flow Metab. 53 383-391.

Chen, Y., Parrish, T.B., 2009. Caffeine dose effect on activation-induced BOLD and CBF responses. Neuroimage 46,577-583.

Chiarelli, P.A., Bulte, D.P., Piechnik, S., Jezzard, P., 2007a. Sources of systematic bias in hypercapnia-calibrated functional MRI estimation of oxygen metabolism. Neuroimage 34, 35-43.

Chiarelli, P.A., Bulte, D.P., Wise, R., Gallichan, D., Jezzard, P., 2007b. A calibration method for quantitative BOLD fMRI based on hyperoxia. Neuroimage 37, 808-820.

Cox, R.W., Jesmanowicz, A., 1999. Real-time 3D image registration for functional MRI Magn. Reson. Med. 42, 1014-1018.

Davis, T.L., Kwong, K.K., Weisskoff, R.M., Rosen, B.R., 1998. Calibrated functional MRI: mapping the dynamics of oxidative metabolism. Proc. Natl Acad. Sci. USA 95, 1834-1839.

Dunn, J.F., O'Hara, J.A., Zaim-Wadghiri, Y., Lei, H., Meyerand, M.E., Grinberg, O.Y., Hou, H., Hoopes, P.J., Demidenko, E., Swartz, H.M., 2002. Changes in oxygenation of intracranial tumors with carbogen: a BOLD MRI and EPR oximetry study. J. Magn. Reson. Imaging 16, 511-521.

Feihl, F., Perret, C., 1994. Permissive hypercapnia. How permissive should we be? Am. J Respir. Crit. Care Med. 150, 1722-1737.

Frackowiak, R.S., Lenzi, G.L., Jones, T., Heather, J.D., 1980. Quantitative measurement of regional cerebral blood flow and oxygen metabolism in man using ${ }^{15} \mathrm{O}$ and positron emission tomography: theory, procedure, and normal values. J. Comput. Assist. Tomogr. 4, 727-736

Gagnon, L., Gauthier, C., Hoge, R.D., Lesage, F., Selb, J., Boas, D.A., 2008. Double-laye estimation of intra- and extracerebral hemoglobin concentration with a time-resolved system. J. Biomed. Opt. 13, 054019.

Glover, G.H., 1999. Deconvolution of impulse response in event-related BOLD fMRI Neuroimage 9, 416-429.

Goode, S.D., Krishan, S., Alexakis, C., Mahajan, R., Auer, D.P., 2009. Precision of cerebrovascular reactivity assessment with use of different quantification methods for hypercapnia functional MR imaging. AJNR Am. J. Neuroradiol. 30, 972-977.

Goodwin, J.A., Vidyasagar, R., Balanos, G.M., Bulte, D., Parkes, L.M., 2009. Quantitative fMRI using hyperoxia calibration: reproducibility during a cognitive Stroop task. Neuroimage 47, 573-580

Griswold, M.A. Jakob, P.M., Heidemann, R.M., Nittka, M.,Jellus, V., Wang J. Kiefer, B. Haase, A., 2002. Generalized autocalibrating partially parallel acquisitions (GRAPPA). Magn. Reson. Med. 47, 1202-1210.

Grubb Jr., R.L., Raichle, M.E., Eichling, J.O., Ter-Pogossian, M.M., 1974. The effects of changes in $\mathrm{PaCO}_{2}$ on cerebral blood volume, blood flow, and vascular mean transit time. Stroke 5, 630-639.

Hoge, R.D., Atkinson, J., Gill, B., Crelier, G.R., Marrett, S., Pike, G.B., 1999a. Investigation of BOLD signal dependence on cerebral blood flow and oxygen consumption: the deoxyhemoglobin dilution model. Magn. Reson. Med. 42, 849-863.

Hoge, R.D., Atkinson, J., Gill, B., Crelier, G.R., Marrett, S., Pike, G.B., 1999b. Linear coupling between cerebral blood flow and oxygen consumption in activated human cortex. Proc. Natl Acad. Sci. USA 96, 9403-9408.

Hoge, R.D., Pike, G.B., 2001. Oxidative metabolism and the detection of neurona activation via imaging. J. Chem. Neuroanat. 22, 43-52.

Ito, H., Kanno, I., Kato, C., Sasaki, T., Ishii, K., Ouchi, Y., Iida, A., Okazawa, H., Hayashida, K. Tsuyuguchi, N., Kuwabara, Y., Senda, M., 2004. Database of normal human cerebral blood flow, cerebral blood volume, cerebral oxygen extraction fraction and cerebral metabolic rate of oxygen measured by positron emission tomography with ${ }^{15} \mathrm{O}$ labelled carbon dioxide or water, carbon monoxide and oxygen: a multicentre study in Japan. Eur. J. Nucl. Med. Mol. Imaging 31, 635-643.

Kemna, L.J., Posse, S., 2001. Effect of respiratory $\mathrm{CO}_{2}$ changes on the temporal dynamics of the hemodynamic response in functional MR imaging. Neuroimage 14, 642-649.

Kemna, L.J., Posse, S., Tellmann, L., Schmitz, T., Herzog, H., 2001. Interdependence of regional and global cerebral blood flow during visual stimulation: an 0-15-butanol positron emission tomography study. J. Cereb. Blood Flow Metab. 21, 664-670.

Kety, S.S., Schmidt, C.F., 1948. The nitrous oxide method for the quantitative determination of cerebral blood flow in man; theory, procedure and normal values. J. Clin. Invest. 27, 476-483.

Kim, S.G., Rostrup, E. Larsson, H.B., Ogawa, S., Paulson, O.B., 1999. Determination of relative CMRO2 from CBF and BOLD changes: significant increase of oxygen consumption rate during visual stimulation. Magn. Reson. Med. 41, 1152-1161.
Landuyt, W., Hermans, R., Bosmans, H., Sunaert, S., Beatse, E., Farina, D., Meijerink, M., Zhang, H., Van Den Bogaert, W., Lambin, P., Marchal, G., 2001. BOLD contrast fMRI of whole rodent tumour during air or carbogen breathing using echo-planar imaging at 1.5 T. Eur. Radiol. 11, 2332-2340.

Lansing, R.W., Gracely, R.H., Banzett, R.B., 2009. The multiple dimensions of dyspnea: review and hypotheses. Respir. Physiol. Neurobiol. 167, 53-60.

Leontiev, O., Buxton, R.B., 2007. Reproducibility of BOLD, perfusion, and CMRO2 measurements with calibrated-BOLD fMRI. Neuroimage 35, 175-184.

Leontiev, O., Dubowitz, D.J., Buxton, R.B., 2007. CBF/CMRO2 coupling measured with calibrated BOLD fMRI: sources of bias. Neuroimage 36, 1110-1122.

Lin, A.L., Fox, P.T., Yang, Y., Lu, H., Tan, L.H., Gao, J.H., 2008. Evaluation of MRI models in the measurement of CMRO2 and its relationship with CBF. Magn. Reson. Med. 60, 380-389.

Liu, T.T., Wong, E.C., 2005. A signal processing model for arterial spin labeling functional MRI. Neuroimage 24, 207-215.

Mark, C.I., Slessarev, M., Ito, S., Han, J., Fisher, J.A., Pike, G.B., 2010. Precise control of endtidal carbon dioxide and oxygen improves BOLD and ASL cerebrovascular reactivity measures. Magn. Reson. Med. (Electronic publication ahead of print).

Ogawa, S., Lee, T.M., Kay, A.R., Tank, D.W., 1990. Brain magnetic resonance imaging with contrast dependent on blood oxygenation. Proc. Natl Acad. Sci. USA 87, 9868-9872.

Perthen, J.E., Lansing, A.E., Liau, J., Liu, T.T., Buxton, R.B., 2008. Caffeine-induced uncoupling of cerebral blood flow and oxygen metabolism: a calibrated BOLD fMRI study. Neuroimage 40, 237-247.

Posse, S., Kemna, L.J., Elghahwagi, B., Wiese, S., Kiselev, V.G., 2001. Effect of graded hypo- and hypercapnia on fMRI contrast in visual cortex: quantification of $\mathrm{T}\left({ }^{*}\right)(2)$ changes by multiecho EPI. Magn. Reson. Med. 46, 264-271.

Rauscher, A., Sedlacik, J., Barth, M., Haacke, E.M., Reichenbach, J.R., 2005a. Nonnvasive assessment of vascular architecture and function during modulated blood oxygenation using susceptibility weighted magnetic resonance imaging. Magn. Reson. Med. 54, 87-95.

Rauscher, A., Sedlacik, J., Deistung, A., Mentzel, H.J., Reichenbach, J.R., 2006. Susceptibility weighted imaging: data acquisition, image reconstruction and clinical applications. Z. Med. Phys. 16, 240-250.

Rauscher, A., Sedlacik, J., Fitzek, C., Walter, B., Hochstetter, A., Kalff, R., Kaiser, W.A., Reichenbach, J.R., 2005b. High resolution susceptibility weighted MR-imaging of brain tumors during the application of a gaseous agent. Rofo 177, 1065-1069.

Reichenbach, J.R., Haacke, E.M., 2001. High-resolution BOLD venographic imaging: a window into brain function. NMR Biomed. 14, 453-467.

Sedlacik, J., Kutschbach, C., Rauscher, A., Deistung, A., Reichenbach, J.R., 2008. Investigation of the influence of carbon dioxide concentrations on cerebral physiology by susceptibility-weighted magnetic resonance imaging (SWI). Neuroimage 43, 36-43.

Sedlacik, J., Rauscher, A., Reichenbach, J.R., 2007. Obtaining blood oxygenation levels from MR signal behavior in the presence of single venous vessels. Magn. Reson. Med. 58, 1035-1044.

Sedlacik, J., Rauscher, A., Reichenbach, J.R., 2009. Quantification of modulated blood oxygenation levels in single cerebral veins by investigating their MR signal decay. Z. Med. Phys. 19, 48-57.

Sedlacik, J., Reichenbach, J.R., 2010. Validation of quantitative estimation of tissue oxygen extraction fraction and deoxygenated blood volume fraction in phantom and in vivo experiments by using MRI. Magn. Reson. Med. 63, 910-921.

Severinghaus, J.W., 1989. Water vapor calibration errors in some capnometers: respiratory conventions misunderstood by manufacturers? Anesthesiology 70, 996-998.

Stefanovic, B., Warnking, J.M., Rylander, K.M., Pike, G.B., 2006. The effect of global cerebral vasodilation on focal activation hemodynamics. Neuroimage 30, 726-734.

van der Sanden, B.P. Heerschap, A. Hoofd, L. Simonetti, A.W Nicolay, K van der Toorn, A., Colier, W.N., van der Kogel, A.J., 1999. Effect of carbogen breathing on the physiological profile of human glioma xenografts. Magn. Reson. Med. 42, 490-499.

Wang, J., Alsop, D.C., Song, H.K., Maldjian, J.A., Tang, K., Salvucci, A.E., Detre, J.A., 2003. Arterial transit time imaging with flow encoding arterial spin tagging (FEAST). Magn. Reson. Med. 50, 599-607.

Wong, E.C., Buxton, R.B., Frank, L.R., 1997. Implementation of quantitative perfusion imaging techniques for functional brain mapping using pulsed arterial spin labeling. NMR Biomed. 10, 237-249.

Worsley, K.J., Liao, C.H., Aston, J., Petre, V., Duncan, G.H., Morales, F., Evans, A.C., 2002. A general statistical analysis for fMRI data. Neuroimage 15, 1-15.

Wu, W.C., Fernandez-Seara, M., Detre, J.A., Wehrli, F.W., Wang, J., 2007. A theoretical and experimental investigation of the tagging efficiency of pseudocontinuous arterial spin labeling. Magn. Reson. Med. 58, 1020-1027.

Yang, Y., Engelien, W., Xu, S., Gu, H., Silbersweig, D.A., Stern, E., 2000. Transit time, trailing time, and cerebral blood flow during brain activation: measurement using multislice, pulsed spin-labeling perfusion imaging. Magn. Reson. Med. 44, 680-685.

Zaharchuk, G., Martin, A.J. Dillon, W.P., 2008. Noninvasive imaging of quantitative cerebral blood flow changes during 100\% oxygen inhalation using arterial spin-labeling MR imaging. AJNR Am. J. Neuroradiol. 29, 663-667.

Zappe, A.C., Uludag, K., Oeltermann, A., Ugurbil, K., Logothetis, N.K., 2008. The influence of moderate hypercapnia on neural activity in the anesthetized nonhuman primate. Cereb. Cortex 18, 2666-2673. 